\title{
Preferential associations of soil fungal taxa under mixed compositions of eastern American tree species
}

Steve Kutos ${ }^{1,2 \S}$, (co-authors) Elle M. Barnes ${ }^{1,2}$, Arnav Bhutada ${ }^{1}$, J.D. Lewis ${ }^{1,2}$

${ }^{1}$ Department of Biological Sciences, Fordham University, Bronx, NY 10458, USA

${ }^{2}$ Louis Calder Center - Biological Field Station, Fordham University, Armonk, NY 10504, USA

${ }^{\S}$ Corresponding Email: skutos@fordham.edu 


\begin{abstract}
Soil fungi are vital to forest ecosystem functions, in part through their role mediating tree responses to environmental factors, as well as directly through effects on resource cycling. While the distribution of these key taxa may vary with a suite of abiotic and biotic factors, the relative role of host species identity on soil fungal community composition and function remains unresolved. In this study, we used a combination of amplicon sequencing and enzymatic assays to assess soil fungal composition and associated function under three tree species, Quercus rubra, Betula nigra, and Acer rubrum, planted individually and in all combinations in a greenhouse, with added fungal inoculum collected below mature field trees. Across treatments, fungal communities were dominated by the phylum Ascomycota, followed by Basidiomycota and Mortierellomycota. Nonetheless, fungal communities differed between each of the solo planted treatments, suggesting at least some taxa may associate preferentially with these tree species. Additionally, fungal community composition under mixed sapling treatments broadly differed from solo saplings. The data also suggests that there were larger enzymatic activities in the solo treatments as compared with all mixed treatments. This difference may be due to the greater relative abundance of saprobic taxa found in the solo treatments. This study provides evidence of the importance of tree identity on soil microbial communities and functional changes to forest soils.
\end{abstract}

Keywords: Soil fungi, tree-fungal interactions, soil microbiome, fungal preference 


\section{INTRODUCTION}

Forests provide globally important ecological and socio-economic functions (Pearce 2001, Butler-Leopold et al. 2018, Moser et al. 2020). They influence nutrient cycles, contain high biodiversity, and are central components of many terrestrial environments in terms of biomass, primary productivity, and land coverage (Pearce 2001, Moser et al. 2020). However, forest trees are under increasing stress from a multitude of factors including climate change, land-use change, habitat fragmentation, and invasive species (Dale et al. 2001, Butler-Leopold et al. 2018, Jo et al. 2019, Moser et al. 2020). Studies have demonstrated that soil fungi can mediate tree responses to these factors (van der Heijden et al. 1998, Hart et al. 2003, Smith \& Read 2010, Fontaine et al. 2011, Karst et al. 2015). This interaction is highly complex: studies of the relative roles of trees and fungi in regulating these interactions have yielded differing results (De Deyn \& Van der Putten 2005, Bardgett \& van der Putten 2014, Lladó et al. 2018). For instance, plant diversity (Bardgett \& van der Putten 2014, Moeller et al. 2015, Prober et al. 2015, Leff et al. 2018, Tedersoo et al. 2020), soil fungal diversity (van der Heijden et al. 1998, 2008, Mangan et al. 2010, Wagg et al. 2011), and soil characteristics (Zobel \& Öpik 2014, Zhou et al. 2016, Baldrian 2017 , Tedersoo et al. 2020) all have been suggested to be the principal factor(s) driving the functionality of this ecosystem dynamic. Therefore, it is critical for the conservation and management of forests that we improve our understanding of this complex tree-fungal interaction.

Soil fungi are globally distributed and are found in high relative abundances in forests (Rousk et al. 2010, Tedersoo et al. 2012, 2014, Talbot et al. 2014). These taxa provide essential ecosystem services including decomposition of organic matter and increasing tree access to limiting nutrients (van der Heijden et al. 1998, Lynd et al. 2002, Smith \& Read 2010). It is well established that both abiotic and biotic factors can lead to spatial differences in soil fungal community composition (Martiny et al. 2006, Tedersoo et al. 2014, 2020). Key abiotic factors include climate characteristics such as precipitation, as well as soil characteristics such as $\mathrm{pH}$ and nutrient availability (Bardgett \& Wardle 2010, Rousk et al. 2010, Tedersoo et al. 2012, 2020, Essene et al. 2017). Biotic factors influencing fungal communities include forest successional stage, microbial species pool, fungal taxa dispersal capabilities, and the 
aboveground tree diversity (Molina \& Trappe 1982, Ishida et al. 2007, Buée et al. 2009, Turner et al. 2009, Bardgett \& Wardle 2010, Peay \& Bruns 2014). A central question, however, is the relative importance of each of these factors on fungal community composition (Guerra et al. 2020).

An unresolved component of this question is the role of tree distributions on the distribution of soil fungal communities. On the one hand, studies have shown a minimal influence of tree species distribution on soil fungal community composition, instead suggesting a primary influence of aforementioned characteristics (Ryberg et al. 2009, Smith et al. 2011, Kennedy et al. 2012, Botnen et al. 2014). Other studies have more closely tied belowground fungal distribution to tree identity and tree phylogenetic relatedness (Molina \& Trappe 1982, De Deyn \& Van Der Putten 2005, Ishida et al. 2007, Tedersoo et al. 2010, Lang et al. 2011, Molina \& Horton 2015, van der Linde et al. 2018). While many soil-fungal taxa are generalists that associate with many tree species, certain taxa appear to have a narrow tree species preference, possibly due to their coevolution (Molina \& Trappe 1982, Massicotte et al. 1999, Klironomos 2000). Fungal preferential association may also arise through several mechanisms, including preferential allotment of tree-derived photosynthate, microbial competition, and tree physiological differences (e.g., modification of soil micro-habitats through root exudates; Dickie 2007, Saunders \& Kohn 2009, Aponte et al. 2010, Kiers et al. 2011). The role of fungal host preferential association may become more complicated when trees are in close proximity, leading fungal community composition to become mixed or possibly skewed towards the community associated with one tree species (Hubert \& Gehring 2008, Hausmann \& Hawkes 2009, Bogar \& Kennedy 2013). A better understanding of the role of neighboring trees on soil fungal communities can provide further insights into how these communities assemble through time and space.

One way to uncover how the distribution of trees influences the distribution and function of soil fungi is understanding the relationship between fungal community composition and changes in fungal exudates. Extracellular enzymes released by fungi break down organic molecules in the local soil area, contributing to nutrient cycling (Burns 1982, Sinsabaugh \& Moorhead 1994, Chalot \& Brun 1998, Lynd et al. 2002, Burns et al. 2013). Functional redundancy among these taxa might be high, nonetheless a 
change in fungal composition may alter enzymatic activities in a local area, altering decomposition rates and soil nutrient storage or release (Burns et al. 2013, Kyaschenko et al. 2017, Looby \& Treseder 2018, Nannipieri et al. 2018). Therefore, spatial differences in fungal community composition associated with differences in tree distributions could lead to altered enzymatic activity, which in turn could impact fungal community composition through effects on nutrient cycling. Accordingly, it is critical to assess changes in production of key enzymes associated with carbon flux and nutrient cycling, and their effects on

59 relationships between tree and soil fungal distributions.

61 distinct from one another and mix if the trees are in close proximity. To address this, we used a greenhouse bioassay with saplings of three common eastern USA tree species, Quercus rubra, Betula nigra, and Acer rubrum, planted individually as well as in paired and triplicate combinations. A fungal inoculate was added to these microcosms, which was collected from soils below mature trees of these same species in the field. We hypothesized that the soil fungal communities of the three tree species would be distinct from one another and decrease in the mixed treatments, due to changes in niche

67 availability and/or interspecific competition. We also examined how potential differences in fungal community composition might result in functional changes in the form of potential activity for six common fungal extracellular enzymes. Finally, we hypothesized that soil enzymatic activity would differ across treatments and will be significantly greater in treatments containing a higher relative abundance of

71 saprobic functional taxa. While interpreting the results of greenhouse bioassays is limited by their

72 simplicity compared to actual forest ecosystems, such studies also minimize confounding effects of

73 abiotic factors that might obscure interpretation of the effects of tree species and fungal community

\section{4 function.}


81

82

83

84

85

86

87

88

89

90

91

92

\section{METHODS}

\section{Experimental bioassay design}

To explore our hypothesies, we performed a greenhouse bioassay at Fordham University's Louis Calder Center in Armonk, NY, USA (coordinates: 41.131789, -73.732911). The Calder Forest is a 113acre protected preserve with a woodland comprising of oaks (Quercus spp.), maples (Acer spp.), American beech (Fagus grandifolia), hickory (Carya spp.), and birch (Betula spp.). The climate is temperate with mean annual temperatures of $12^{\circ} \mathrm{C}$ and mean annual precipitation of $120 \mathrm{~cm}$. The soil is acidic sandy loam. Experimental tree species were obtained as $\sim 30 \mathrm{~cm}$ tall bareroot saplings from Cold Stream Farm (Freesoil, MI, USA). In autumn 2018, each sapling was planted individually in a sterilized $3.8 \mathrm{~cm}$-wide cone-tainer pot (Steuwe and Sons, Tangent, OR, USA) with field-collected soils. These soils were collected from underneath five randomly selected mature trees for each experimental species at least $30 \mathrm{~m}$ apart in the Calder Forest. Roughly $6 \mathrm{~kg}$ of soil for each tree species was collected and homogenized so that each experimental sapling received the same soil source.

In early spring 2019, saplings of similar height of each species were randomly selected from this stock for use within the bioassay. Saplings were then moved into sterilized C1200 11-liter plastic pots with a 2:1 volumetric mixture of soil mix (Pro-Mix BX, Premier Tech Horticulture, Quakertown, PA, USA) and autoclaved sand (Sakrete, Charlotte, NC, USA). Pro-Mix BX soil is a general-use, nonmycorrhizal mixture containing sphagnum peat moss, perlite, limestone, and vermiculite. In the greenhouse, the pots were arranged in a randomized block design with $\sim 15 \mathrm{~cm}$ spacing between pots to reduce crowding (12 blocks x 8 treatments). Treatments were: (1) Controls: pots with no trees, (2) Solo Planted: one sapling from each species planted alone, (3) Paired Planted: two different tree species planted together in all pairwise combinations, and (4) Triple Planted: all tree species planted together. For the pair and triple plantings, each individual was placed in the pot roughly equidistant apart with a few centimeters spacing from the edge. To these containers, a soil fungal inoculum was added for each species within the treatment to obtain a representative fungal diversity mimicking field condition. The fungal 
inoculate were created from soils taken from underneath the same trees used for the initial planting substrate and contained a mixture of $500 \mathrm{~mL}$ sterile $\mathrm{diH}_{2} \mathrm{O}$ and $100 \mathrm{~mL}$ soil. Controls received the same 2:1 ratio of soil to autoclaved sand, but without added inoculum, to account for fungal taxa within the Pro-Mix $B X$. Soil moisture and $\mathrm{pH}$ were evaluated monthly to confirm treatments were under similar conditions during the experiment. Soil $\mathrm{pH}$ was measured using a 2:1 ratio of distilled water to soil on an Accumet AE150 probe (ThermoFisher Scientific, Waltham, MA, USA), and soil moisture was measured by drying $5 \mathrm{~g}$ of soil for $24 \mathrm{~h}$ at $105^{\circ} \mathrm{C}$.

\section{Soil sampling, DNA sequencing, and bioinformatics}

In early winter 2019 , three soil cores $(\sim 8 \mathrm{~cm}$ depth) were collected from each pot and pooled into one soil sample per treatment. The soil corer was sterilized with $10 \%$ bleach and $70 \%$ ethanol prior to

117 each sampling. Soil cores were sieved through a sterilized $2 \mathrm{~mm}$ screen and stored at $-20^{\circ} \mathrm{C}$. Fungal DNA

118 was extracted from $0.25 \mathrm{~g}$ of soil using the Qiagen PowerSoil DNA Kit (Qiagen Inc., Mississauga,

119 Canada) and PCR targeted the ITS1 region using the forward primer ITS1F and barcoded reverse primer

120 ITS2 (White et al. 1990, Gardes \& Bruns 1993, Smith \& Peay 2014). PCR reactions (25 $\mu$ l) contained: primers $(10 \mu \mathrm{M}), 0.5 \mu \mathrm{l} 10 \mathrm{mM}$ dNTPs, $1.0 \mu \mathrm{l} \mathrm{BSA}$, and $2 \mu \mathrm{l}$ of extracted DNA. Amplifications were performed on an Applied Biosystems thermocycler (Model 2720, Foster City, CA, USA) under the following conditions: $94^{\circ} \mathrm{C}$ for $1 \mathrm{~min}$, followed by $94^{\circ} \mathrm{C}$ for $30 \mathrm{~s}, 58^{\circ} \mathrm{C}$ for $30 \mathrm{~s}, 68^{\circ} \mathrm{C}$ for $30 \mathrm{~s}$ for 35 cycles, and $68^{\circ} \mathrm{C}$ for $7 \mathrm{~min}$. Amplicons were purified using Sera-Mag Speedbeads ${ }^{\mathrm{TM}}$ (GE Healthcare,

127 Carlsbad, CA, USA). Amplicon libraries, including positive and negative controls, were normalized,

128 pooled, and then sequenced on an Illumina 2 x 250 bp MiSeq at Genewiz (Brooks Life Sciences

129 Company, South Plainfield, NJ, USA). The positive sequencing control contained ten known fungal taxa 130 from the phyla Basidiomycota, Ascomycota, and Mortierellomycota. Demultiplexed FASTQ files were 131 filtered and processed using a QIIME2 bioinformatic pipeline (Release: 2020.8; Caporaso et al. 2010). 
Sequencing adapters, fungal primers, and low-quality bases were first trimmed using ITSXpress and cutadapt (Martin 2011, Rivers et al. 2018). Trimmed reads were processed and merged using DADA2 to produce ASVs (Callahan et al. 2016) and then aligned via the UNITE database to assign them to taxonomic groups (Version 8.2, Abarenkov et al. 2010). ASVs that did not match taxa within the database were listed as unclassified fungal ASVs. ASVs classified as non-fungi were removed. These ASVs were rarified to a depth of 7025. Finally, taxonomic assignments were processed in FUNGuild to assign ASVs to functional groups using only highly probable and probable assignments (Nguyen et al. 2016).

\section{Fluorometric enzymatic assay}

To obtain fungal enzymatic potential activity, soils were run through a high-throughput standardized fluorescence assay developed by Bell et al. (2013) using 4-methylumbelliferone as a fluorescent indicator (Jacks \& Kircher 1967, Marx et al. 2001, Courty et al. 2005). Six evaluated enzymes were selected due to their abundance in soils and their role in the degradation of carbon and phosphorus substrates (Supplemental Table 1; Nannipieri et al. 2012, Burns et al. 2013). Factorial tests runs were conducted to determine maximum yields using different $\mathrm{pH}$ levels found in the area $(4.0-6.0)$, addition

147 of $\mathrm{NaOH}$, different incubation times ( $3-6$ hours), and multiple read settings as recommended in the 148 protocol (Bell et al. 2013). Soil slurries for each sample were created by combining $2.75 \mathrm{~g}$ of soil and 91 $\mathrm{ml}$ of $50 \mathrm{mM}$ sodium acetate buffer. From these slurries, $800 \mathrm{ul}$ of each sample was added randomly to a 96 deep-well plate and incubated for $3 \mathrm{~h}$ in the dark at room temperature $\left(\sim 23^{\circ} \mathrm{C}\right)$ and then centrifuged 151 for $30 \mathrm{~min}$ at $2300 \mathrm{x}$ g. From the supernatant, $200 \mathrm{ul}$ of each sample was added to corresponding black,

152 flat-bottom plates and read on a SpectraMax M2e microplate reader (Molecular Devices, San Jose, CA, 153 USA), with an excitation wavelength at $365 \mathrm{~nm}$ and emission wavelength at $450 \mathrm{~nm}$. To improve

154 fluorescence yields, $10 \mathrm{ul}$ of $\mathrm{NaOH}$ was added to each well roughly two minutes prior to plate reading

155 (DeForest 2009, Bell et al. 2013). All assays were completed within $72 \mathrm{~h}$ of soil collection to avoid 156 suppressing activity (DeForest 2009). Negative controls consisting of only a solution of the buffer and 
substrate used for each sample. Enzymatic activities were corrected by applying this control and converted to $\mathrm{nmol} \mathrm{h} \mathrm{h}^{-1} \mathrm{~g}^{-1}$.

\section{Statistical analysis}

All analyses were completed in $\mathrm{R}$ (Version 4.0.1) using the phyloseq, vegan, microbiome packages (Oksanen et al. 2007, McMurdie \& Holmes 2013, Lahti et al. 2017). Alpha diversity was measured as ASV richness and by the Shannon index and diversity was compared among treatments using an ANOVA including block as a random effect, followed by Tukey's HSD tests for pairwise comparisons. Levene's tests and histograms were used to assess normality and homogeneity of variances. Beta diversity was measured by calculating Bray-Curtis dissimilarities on log-transformed read counts.

171 abundant ASVs in each of the major phyla using the function aheatmap with the rows converted to

172 standardized Z-Scores. Indicator species analysis was performed to examine which ASVs were distinctive

173 to each treatment using the indicspecies package with 9999 Monte Carlo permutations (Cáceres \&

174 Legendre 2009). Enzyme values obtained from the fluorometric assay were compared using an ANOVA

175 with a Tukey's HSD for pairwise comparisons. Enzymatic activity values underwent a log transformation

176 prior to analysis due to skewness. Graphs were constructed using the ggplot2 package (Wickham et al.

177 2016).

\section{RESULTS}

\section{Soil fungal community diversity patterns}

In total, our samples contained 1,581 unique ASVs ( $3.65 \times 10^{5}$ sequences from 52 samples). The 
with lesser numbers in the Basidiomycota (14.0\%), and Mortierellomycota (2.5\%; Fig. 1,2). The ten most relative abundant ASVs across all treatments were also members of Ascomycota (orders: Pezizales, Xylariales, Saccharomycetales, Coniochaetales, Thelebolales) and Basidiomycota (order: Tremellales). There were only two ASVs found within all treatments belonging to the order Saccharomycetales within Ascomycota.

All solo planted treatments had a greater relative abundance of the phylum Ascomycota as compared to the mixed planted treatments (Fig. 1, 2, 3a). Alongside this shift, there were also clear differences in the relative abundance of the other two fungal phyla, Basidiomycota or Mortierellomycota, from the solo treatments to the mixed planted treatments. The solo Quercus rubra treatments had the greatest relative abundance of the fungal family Pezizaceae (53\% of reads), along with the family Orbiliaceae (14.9\%), and an unidentified family within the order Xylariales (11.3\%; Fig. 1a). The solo Acer rubrum treatments also had the greatest relative abundance of Pezizaceae (50.4\% of reads), along with an unidentified family within the order Xylariales (15.7\%), as well as the family Coniochaetaceae (14.5\%, Fig. 1a). In the solo Betula nigra treatments, the families Pezizaceae (18.5\% of reads), Pseudeurotiaceae (15.4\%), Coniochaetaceae (14.5\%, Fig. 1a) had the highest relative abundance. ASVs in Pezizaceae in the solo B. nigra treatments were $\sim 2.5 \mathrm{X}$ lower in relative abundance from the other solo treatments.

When Q. rubra was paired with A. rubrum, taxa in the family Pezizaceae (32\% of reads) and the unidentified family within the order Xylariales (6.3\%) had lower relative abundances by $1.6 \mathrm{X}$ and $1.8 \mathrm{X}$ respectively compared to the solo Q. rubra treatments (Fig. 2a). However, these two families had the highest relative abundance in this paired treatment along with the family Trimorphomycetaceae $(8.4 \%$, Fig. 2a). Taxa in the family Trichomonascaceae, which were highly abundant in the solo $\mathrm{A}$. rubrum treatments, were $7 \mathrm{X}$ lower in abundance when paired with $Q$. rubra, matching the relative abundance in the solo Q. rubra treatments (Fig. 2a). Further, taxa within Mortierellaceae were 6X greater in relative abundance in this paired treatment when it was rare in both solo sapling treatments $(<0.1 \%$ of reads; Fig. 2a, 3c). When $B$. nigra was paired with $A$. rubrum, the diversity pattern changed with taxa in the family 
Trichomonascaceae ( $26.4 \%$ of reads) having the highest relative abundance along with an unidentified

family in the order Xylariales (16.2\%) and the family Pezizaceae (16.0\%; Fig. 2a). Therefore, only in this

211 paired treatment does the family Trichomonascaceae have a higher relative abundance as compared to

212 both solo sapling treatments. The family Pseudeurotiaceae, which was highly abundant in the solo $B$.

213 nigra treatments, had a 5X lower relative abundance, similar to abundances found in the solo $\mathrm{A}$. rubrum

214 treatments $(2.8 \%$ of reads; Fig. 2a).

215 When B. nigra was paired with Q. rubra, the families Pezizaceae (26.7\% of reads), an

216 unidentified family in the order Xylariales (18.8\%), and Mortierellaceae (7.9\%) had the highest relative

217 abundances (Fig. 2a). Thus, taxa within Mortierellaceae were 6X greater in relative abundance only in

218 this paired treatment compared the solo sapling treatments (Fig. 2, 3c). Highly abundant families in the

219 solo B. nigra treatments were lower in relative abundance only when paired with $Q$. rubra, including

220 Pseudeurotiaceae ( $15.4 \%$ to $3.8 \%$ of reads), Coniochaetaceae ( $14.5 \%$ to $7 \%$ of reads), and

221 Trichomonascaceae (13.7\% to $2 \%$ of reads). This pattern was also seen with high relative abundant

222 families in the solo Q. rubra treatments including Orbiliaceae (15\% to $0.8 \%$ of reads) and Pezizaceae

$223 \quad(53 \%$ to $27 \%$ of reads).

When all three tree species were planted together, the highest relative abundance was in the taxa

(6.3\%; Fig. 2). Taxa in Trichomonascaceae and Coniochaetaceae, which had high relative abundances in

the $B$. nigra and A. rubrum solo treatments, were $4 \mathrm{X}$ and 10X less abundant with respect to the triplesaprobic taxa displayed no distinct pattern.

Fungal communities differed significantly among treatments in Shannon diversity $(F=3.78, p=$ 0.003; Fig. 1b, 2b) and ASV richness $(F=7.49, p<0.001$; Fig. 1c, 2c). Diversity and ASV richness in

233 solo treatments differed from that in the mixed sapling treatments, with greater diversity $(\sim 1.5 \mathrm{X})$ and

234 richness $(\sim 1.5 \mathrm{X})$ in the paired and triple-plated treatment (Fig. 1, 2). Community composition also 
differed significantly $\left(F=3.35, p<0.001, \mathrm{r}^{2}=0.22\right.$; Fig. 1, 2). There were significant differences in the fungal composition between each solo planted treatment as well as between the solo planted treatments and mixed planted treatments ( $p<0.01$; Supplemental Table 2). When we looked only at the mixed planting treatments, we found significant differences in the fungal composition of all paired treatments except between the $Q$. rubra + A. rubrum and the $Q$. rubra $+B$. nigra treatments $(p<0.01$;

Supplemental Table 2). Finally, we found no differences in composition between the triple-planted and paired-planted treatments except for the triple-planted versus B. nigra + A. rubrum treatment $(p<0.01$;

\section{Supplemental Table 2).}

Indicator species analysis was used to detect ASVs that may significantly associate with one tree species over the others or with one tree species combination. Five fungal ASVs were identified as indicator ASVs in the solo- and paired planted treatments $(p<0.01)$. Of note, the relative abundances of these indicator taxa were low $(<0.1 \%$ of reads). An unidentified ASV in the family Herpotrichiellaceae and an ASV in the family Geminibasidiaceae were identified as indicator ASVs in the solo Q. rubra of the Q. rubra + A. rubrum had one indicator ASV in the family Trimorphomycetaceae. The remaining treatments included no indicator ASVs $(p>0.01)$.

\section{Enzyme activity patterns}

Two enzymes assessed, $\alpha$-Glucosidase and $\beta$-glucuronidase, displayed no detectable activity via the fluorometric assay, so they were removed from statistical analyses. The activities for the remaining

256 four enzymes were significantly different among treatments except for $\beta$-xylosidase, which did not vary

257 by treatment $(p>0.05$; Fig. 4c). The enzymatic potential activity of $\beta$-Glucosidase was significantly

258 different between the treatments. This difference was mainly detected in the solo $A$. rubrum and solo $B$.

259 nigra treatments, which had $\beta$-Glucosidase activity levels that were $3 \mathrm{X}$ higher than all other treatments $(p$

$260<0.001 ;$ Fig. 4a). The enzymatic potential activity of cellobiohydrolase was also significantly different 
between treatments. In particular, cellobiohydrolase activity was $4 \mathrm{X}$ higher in the solo A. rubrum and $B$. nigra treatments (Fig. 4d). Acid phosphatase activity was 3.5X higher in all three solo treatments as

263 compared to all mixed treatments $(p<0.001$; Fig. 4b). As expected, the no-sapling controls showed no

264 discernible activity for any of the enzymes evaluated.

\section{DISCUSSION}

This study investigated the effects of tree identity and composition on fungal communities in temperate forest soils. Overall, soil fungal community composition differed with tree sapling species identity. Further, the soil fungal communities of the solo planted treatments differed from the mixed planted treatments, indicating that these three tree species can develop distinct fungal communities and

271 that when proximal, their associated fungal communities' mix. In addition, we observed that differences

272 in fungal community composition were associated with altered activity of enzymes. By reducing

273 environmental variation associated with field studies, this greenhouse bioassay provides a more direct

274 exploration of tree-host preferential association among soil fungal taxa.

Consistent with our first hypothesis regarding solo planted treatments, the soil fungal

276 communities associated with each of the three tree species, Acer rubrum, Quercus rubra, and Betula

277 nigra, differed in community diversity and composition. This was anticipated due to the relatively distant

278 phylogenetic relatedness of these tree species, which has a positive relationship with soil fungal

279 community composition (Molina \& Trappe 1982, Ishida et al. 2007, Tedersoo et al. 2013). Overall, there

280 were taxonomic patterns distinguishing these communities. As one example, taxa in the fungal class

281 Leotiomycetes (phylum: Ascomycota) and fungal families Pyronemataceae (phylum: Ascomycota) and

282 Phanerochaetaceae (phylum: Basidiomycota) were only highly abundant in the solo $B$. nigra treatments

283 suggesting robust tree species preferential association. These fungal groups do have known associations

284 with Betula spp., although not exclusively, suggesting potential preferential association, but not 
2019). These findings provide further evidence that tree species can associate with distinct fungal

287 communities.

When we compared both solo and mixed planted treatments, we found a few fungal families that had high relative abundances in all treatments. This implies that most of the fungal taxa found within these communities are tree species or environmental condition generalists and might be able to associate with multiple tree species (Ishida et al. 2007, Urbanová et al. 2015). This is further bolstered by the lack of an broad influence of one tree species' distinct fungal community 'overwhelming' the communities of the other trees (Mummey et al. 2005, Hausmann \& Hawkes 2009). However, soil fungal community composition in the solo planted treatments was significantly different from the mixed planted treatments. For instance, taxa in the fungal family Tremellomycetes (phylum: Basidiomycota) were only abundant in treatments containing a $Q$. rubra. These taxa are common soil residents in temperate forests and have diverse morphologies and nutrient acquisition strategies (Edwards \& Zak 2010, Millanes et al. 2011, Liu et al. 2015, Mašínová et al. 2017). Their apparently specific association in the present study with $Q$. rubra is of interest and warrants further study. A different pattern was found with the family Trichomonascaceae (phylum: Ascomycota) which was only abundant in treatments lacking Q. rubra, suggesting either preferential association for B. nigra and A. rubrum, or a preferential aversion to $Q$. rubra. This family of yeasts has seen limited study; however, they do belong to a fungal group that may be sensitive to increased microbial competition and changes in nutrient conditions (Kurtzman \& Robnett 2007, Li et al. 2021).

Greater fungal richness and diversity in the mixed planted treatments seemed to be driven at least partially by the higher relative abundances of taxa from the phyla Mortierellomycota and Basidiomycota. Taxa within Mortierellomycota are common soil saprobic residents that can form a mycorrhizal-like symbiosis with many tree hosts (Uehling et al. 2017, Johnson et al. 2019). Similarly, some taxa within Basidiomycota prefer colonizing the roots of multiple hosts (Molina \& Trappe 1982, Horton \& Bruns 1998, Massicotte et al. 1999, Smith \& Read 2010). This may help to explain why these taxa had higher relative abundances in the mixed planted treatments, especially given that saplings in the bioassay were 
312 planted relatively close together. Further, studies have suggested that when certain fungal taxa are already

313 colonized on one tree root, proximal plants can prompt sporulation and germination, thus increasing the

314 opportunity of multi-tree colonization (Hubert \& Gehring 2008, Bogar \& Kennedy 2013, Bogar et al.

315 2015). Interestingly, Basidiomycota taxa had different distributions between the mixed treatments

316 depending on tree composition. For example, closely related genera Lactarius and Russula (order:

317 Russulales) were more abundant in separate mixed treatments (Lactarius: Q. rubra + A. rubrum and

318 triple-planted treatments; Russula: Q. rubra + B. nigra treatments). This pattern further supports evidence

319 from other studies that these genera can be host-specific if preferred hosts are available but also host generalists if only non-preferred hosts are available (Tedersoo et al. 2008, Morris et al. 2009, Wilson et al.

2017, Looney et al. 2018). In sum, our results suggest that the mixed plantings may work to synergistically provide a more suitable environment for certain fungal taxa, leading to their relative abundances being greater. relative abundance of the genera Chromelosporium and Sphaerosporella which are commonly found within greenhouse experiments (Hennebert \& Korf 1975, Sánchez et al. 2014). compositional variation within these treatments. This indicates that our bioassay communities are likely

334 impacted by unmeasured factors, such as a legacy effect (Gao et al. 2020). Our mixed planted fungal 335 inoculum consisted of a combination of soils found under each of the tree species in the field, rather than 336 a single soil inoculum from a location where all three tree species grew side-by-side. We also cannot rule 337 out the influence of artificially combining our fungal inoculum with any communities found in our 
greenhouse potting soil. Both events could have led our bioassay communities to mix in a slightly different way than might naturally happen in the field (Rillig et al. 2016, Castledine et al. 2020).

340 Nonetheless, these findings might have important ecological impacts in eastern USA forests as fungal

341 taxa that may be generalists, especially mycorrhizal fungi, could facilitate heterospecific sapling

342 establishment and sapling development (Nara 2006, Dickie \& Reich 2005, Dickie 2007, Wolfe \& Pringle

343 2012).

\section{Enzymatic activity shifts among different tree compositions}

Tree identity and composition have the potential to influence the enzymatic activity in soils by creating distribution patterns of fungal taxa with specific functional roles. The activities of $\beta$-glucosidase, cellobiohydrolase, and acid phosphatase were significantly higher in the solo planted treatments. One potential explanation for this is the higher relative abundance of particular saprobic taxa, which are known to emit extracellular enzymes, as well as the higher relative abundance of mycorrhizal taxa in the be able to utilize simple sugars and not complex polymers (Poll et al. 2010, Ellegaard-Jensen et al. 2013, Uehling et al. 2017, Koechli et al. 2019).

Of note, these soils did not significantly differ in sapling age or soil characteristics such as $\mathrm{pH}$ and soil moisture levels which are known influencers of enzymatic activity differences (Brockett et al. 2012, Baldrian 2014, Kivlin \& Treseder 2014). However, other untested soil conditions, as well as root 360 exudates, may have contributed to the differences in enzymatic activities (Strickland et al. 2009, Kivlin \&

361 Treseder 2014). Additionally, only six enzymes were evaluated individually here which may miss other

362 important enzymes present within these soils and/or the potential synergistic effect of multiple enzymes on soil substrates (Baldrian et al. 2014, Kivlin \& Treseder 2014). Soil enzymatic activity is a dynamic 
364 process influenced by many factors, including other microbial groups, so caution should be used in

365 interpreting this bioassay data (Boer et al. 2005, Romaní et al. 2006, Strickland et al. 2009, Glassman et

366 al. 2018). Nevertheless, these results do add evidence to the relative importance of tree species and

367 associated soil fungal communities on extracellular enzymatic activity.

\section{Conclusion}

Data from this greenhouse bioassay indicate that different tree species can have significantly

371 different soil fungal communities and that these communities can influence the fungal communities of

372 proximal trees. These results match those from other tree-fungal systems. Additionally, the mixing of

373 these fungal communities was associated with lower potential enzymatic activity. Forests in the eastern

374 USA are not static; tree diversity and composition are changing alongside a changing climate. This data

375 provides further evidence that altering the distribution and diversity of aboveground trees in these forests

376 may impact belowground soil fungal communities. We acknowledge that this greenhouse bioassay was

377 performed on young saplings which may have resulted in an increased influence of spore-based, early

378 arriving fungal taxa. However, as this and other studies demonstrate, the diversity and richness patterns

379 found here have the potential to relate to fungal communities in situ. To further explore these

380 relationships, future experiments could include varied environmental conditions, more distant

381 phylogenetic tree species, as well as a longer experimental period. Disentangling the factors that influence

382 forest trees and soil fungal is of utmost importance given the vast array of ecosystem services provided by

383 these two intertwined communities. 
Figure 1 Soil Fungal Diversity in Solo Planted Treatments. a: Relative abundance of the top nine families for all solo treatments. $b$ : Boxplot of Shannon index of soil fungal communities among solo treatments. c: Boxplot of ASV richness of soil fungal communities among solo treatments. d: NMDS ordination of Bray-Curtis distances of the solo treatments.

a
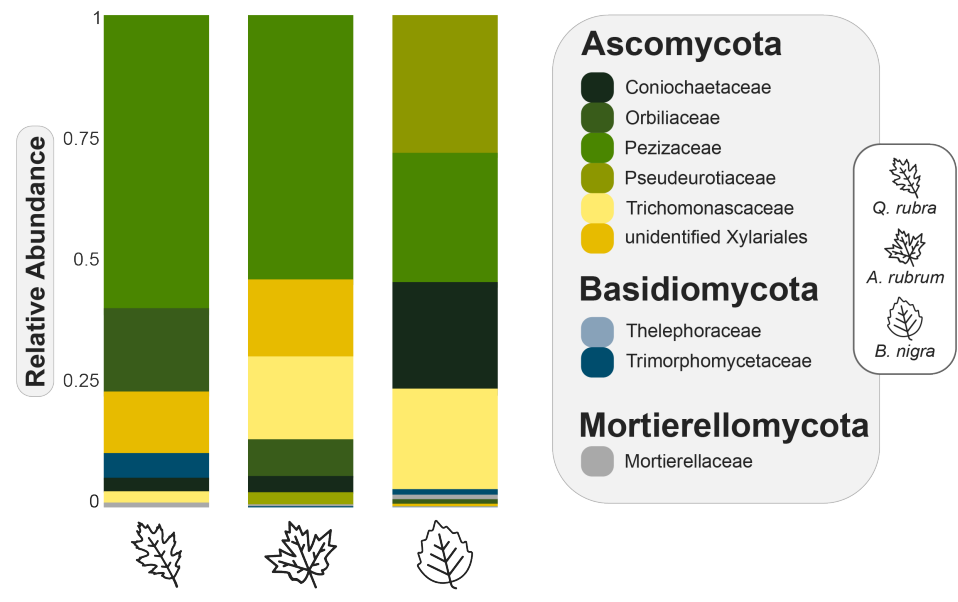

Mortierellomycota

Mortierellaceae

b

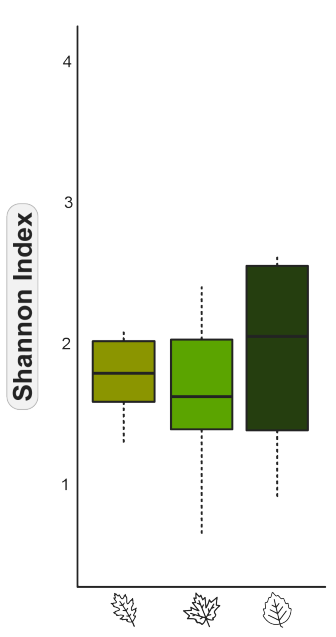

C

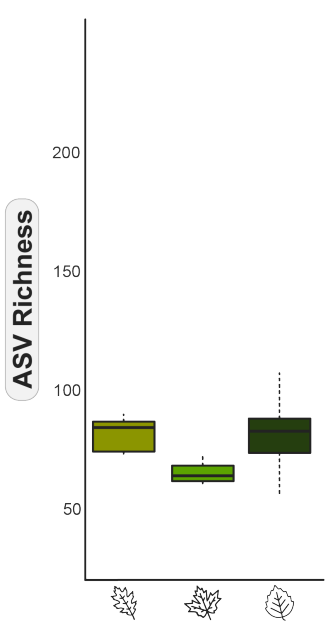

d

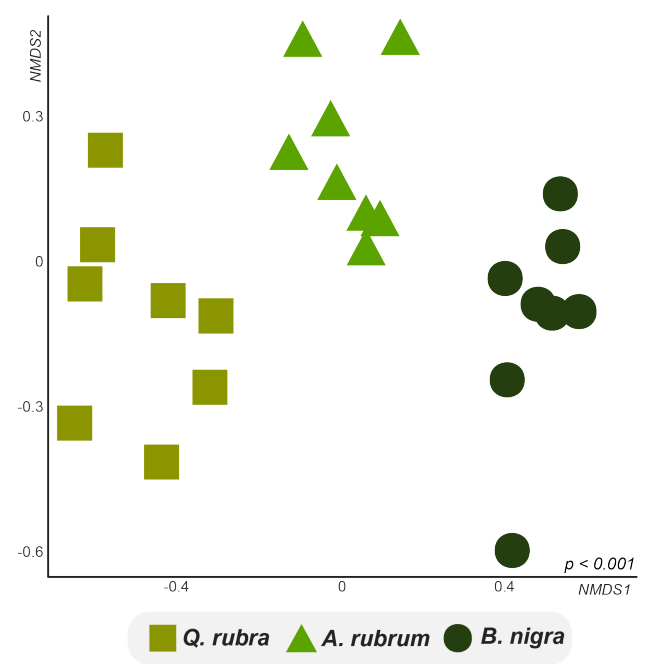


Figure 2 Soil Fungal Diversity in Mixed Planted Treatments a: Relative abundance of the top

394 nine families for all mixed treatments. b: Boxplot of Shannon index of soil fungal communities

395 among mixed treatments. c: Boxplot of ASV richness of soil fungal communities among mixed

396 treatments. d: NMDS ordination of beta diversity of all solo and mixed treatments.

a
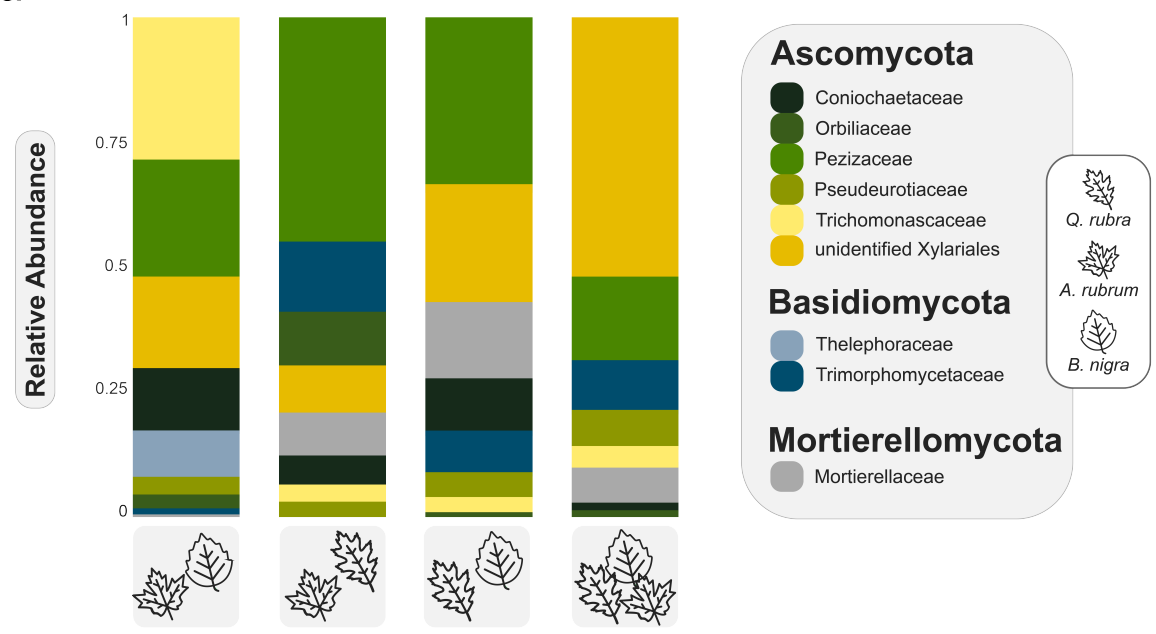

\section{Mortierellomycota}

Mortierellaceae

b

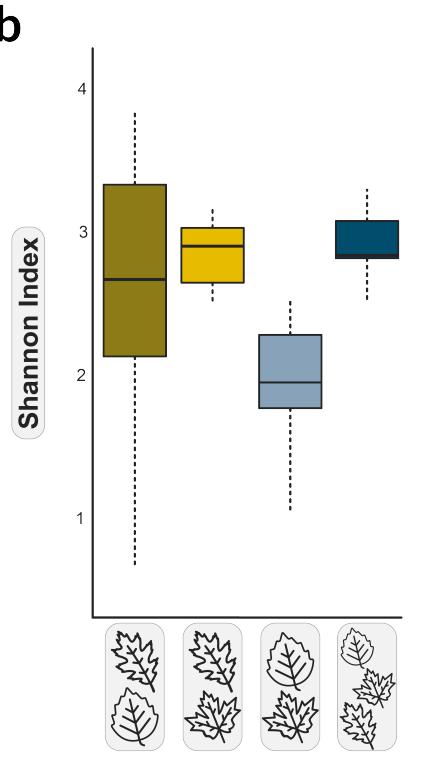

C

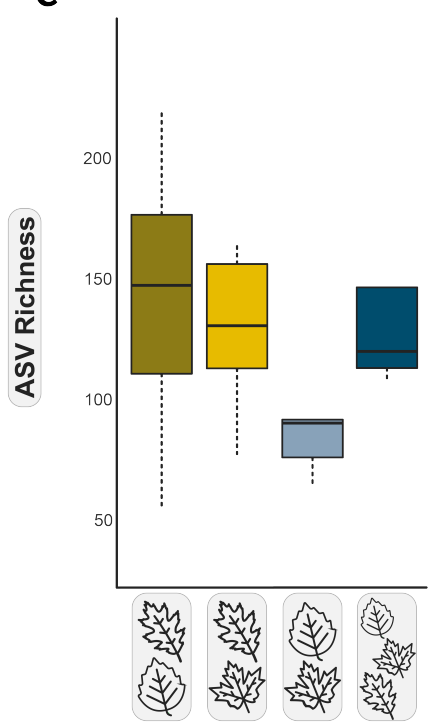

d

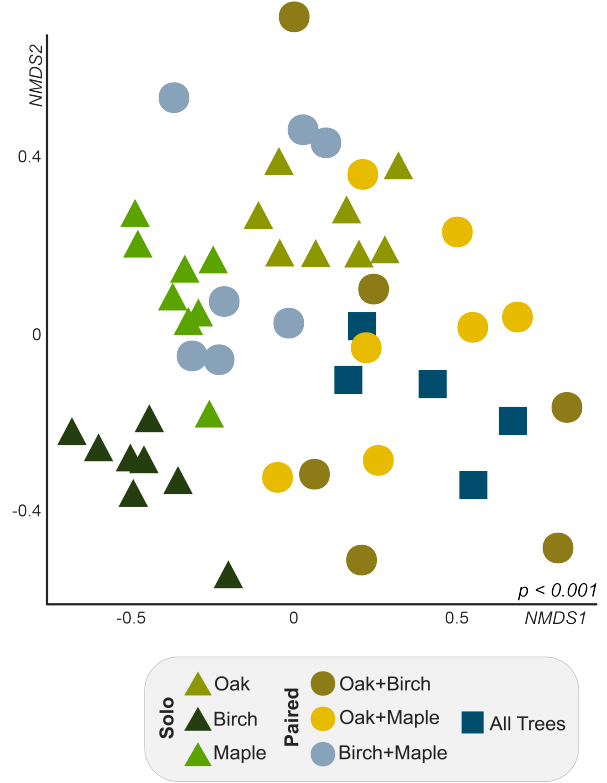


Figure 3 Distribution of fungal ASVs across treatments using Z-Scores. a: 20 most abundant

401 Basidiomycota ASVs across treatments. b: 20 most abundant Ascomycota ASVs across

402 treatments. c: 20 most abundant Mortierellomycota ASVs across treatments. Fungal classes are

403 listed on the left of each graph.

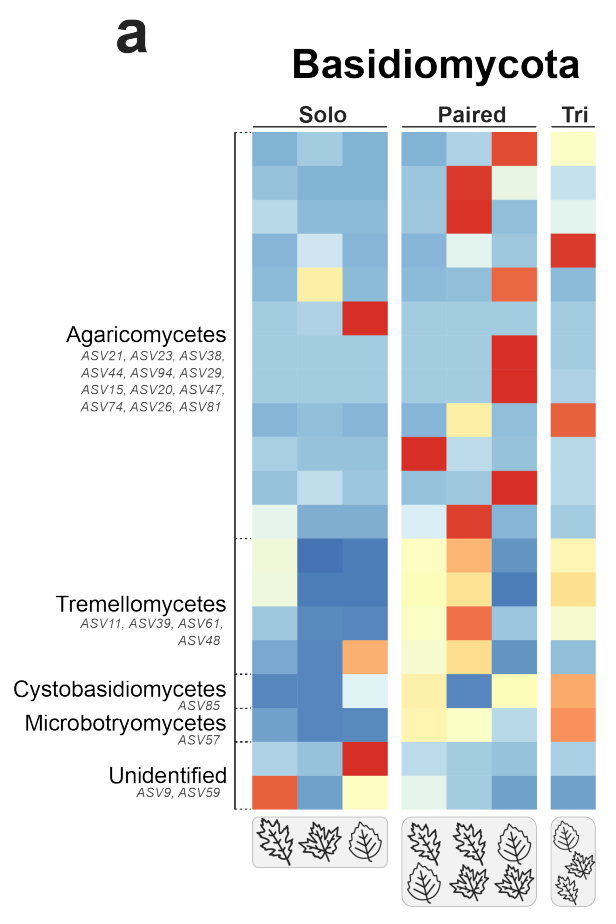

Mortierellomycota

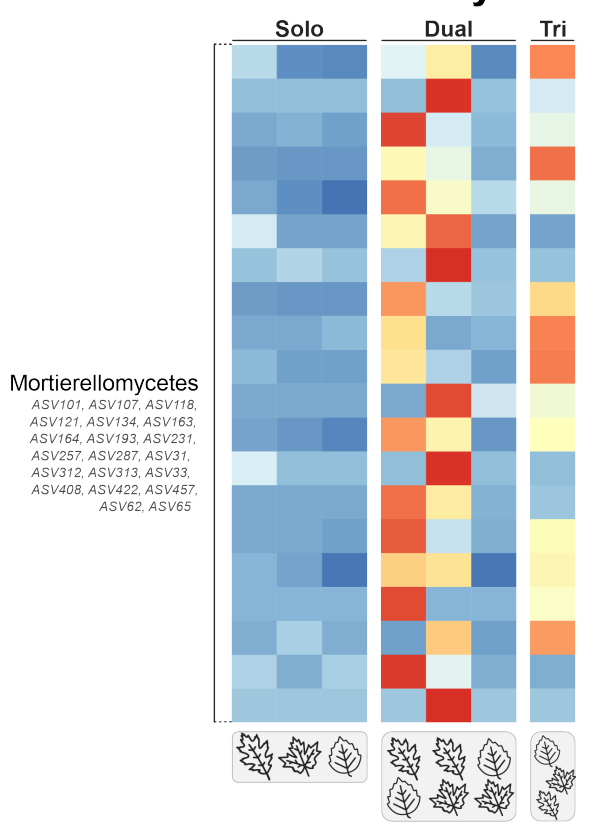

b

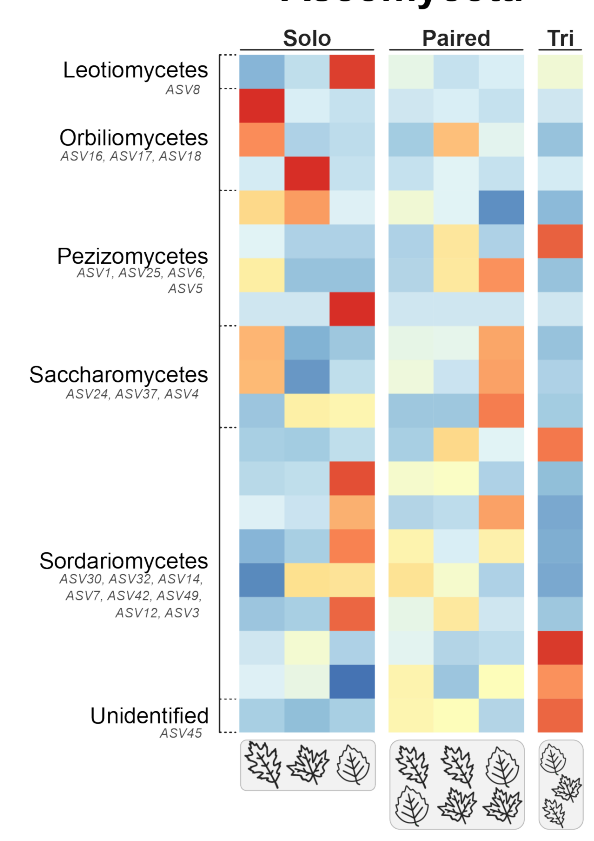

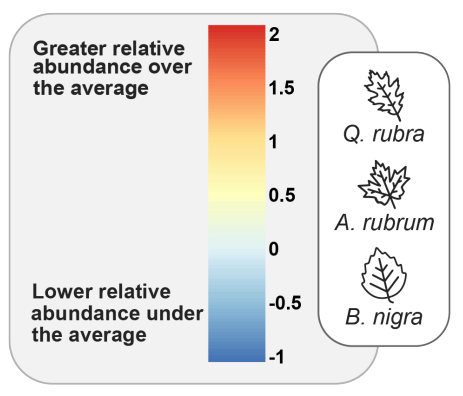


404 Figure 4. a: Boxplot of log-transformed enzymatic activity for $\beta$-glucosidase $(p<0.05)$. b:

405 Boxplot of log-transformed enzymatic activity for acid phosphatase $(p<0.05)$. c: Boxplot of log-

406 transformed enzymatic activity for $\beta$-xylosidase (ns, $p>0.05$ ). d: Boxplot of log-transformed

407 enzymatic activity for cellobiohydrolase $(p<0.05) . \mathbf{O}=$ solo $Q$. rubra, $\mathbf{M}=$ solo $A$. rubrum, $\mathbf{B}=$

408 solo B. nigra, $\mathbf{O}+\mathbf{B}=$ paired $Q$. rubra and $B$. nigra, $\mathbf{O}+\mathbf{M}=$ Paired $Q$. rubra and $A$. rubrum,

$409 \mathbf{B}+\mathbf{M}=$ paired $B$. nigra and $A$. rubrum, and $\mathbf{A l l}=$ treatment of all three experimental species. All

410 values are nmol h $\mathrm{h}^{-1} \mathrm{~g}^{-1}$. Letters denote significant Tukey's HSD.

a

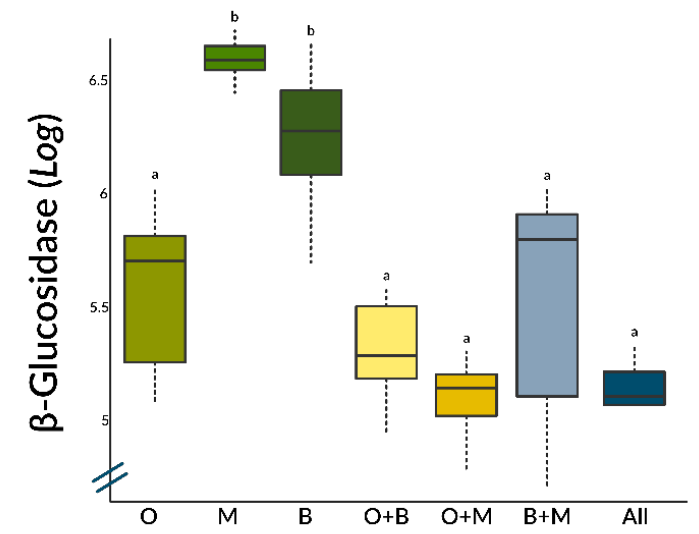

C

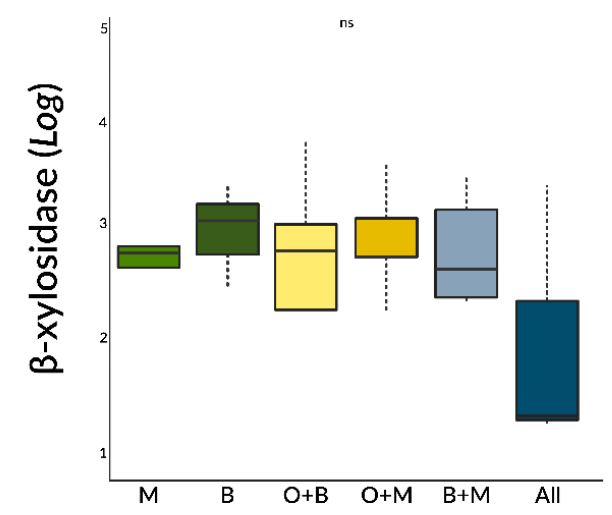

b

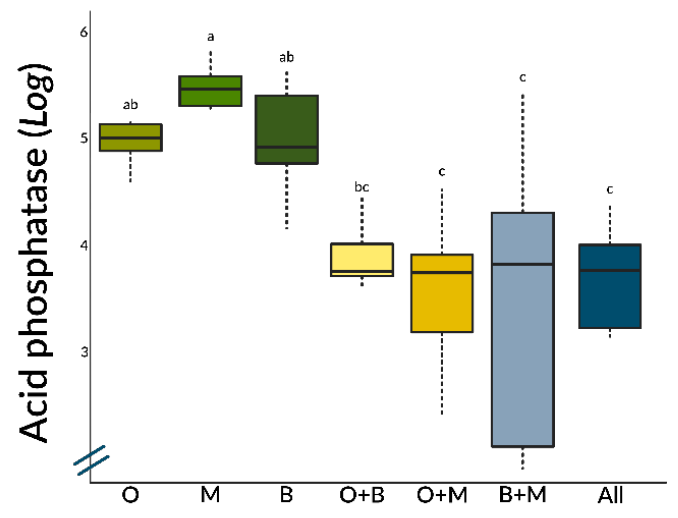

d

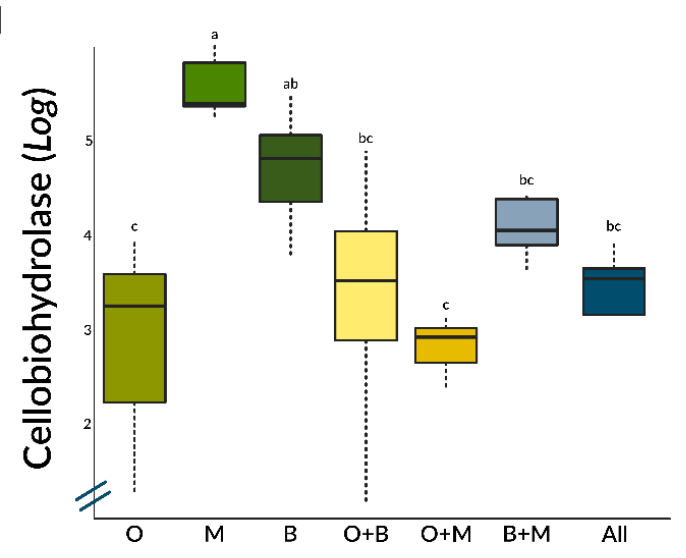


414 Supplemental Table 1 List of enzymes evaluated, the associated reagents used, and their

415 ecological roles.

\begin{tabular}{|c|c|c|}
\hline Enzyme & Reagent & Enzymatic Action \\
\hline $\begin{array}{l}\text { Cellobiohydrolase } \\
(\mathrm{CBH})\end{array}$ & 4-MUB- $\beta$-D-cellobioside & C Cycle: Degrades cellulose \\
\hline$\beta$-Glucosidase (BG) & $\begin{array}{l}\text { 4-MUB } \beta \text {-D- } \\
\text { glucopyranoside }\end{array}$ & C Cycle: Degrades cellulose \\
\hline$\alpha$-Glucosidase (AG) & $\begin{array}{l}\text { 4-MUB } \alpha \text {-D- } \\
\text { glucopyranoside }\end{array}$ & C Cycle: Degrades cellulose \\
\hline Acid phosphatase (AP) & 4-MUB Phosphate & $\begin{array}{l}\text { P cycle: Phosphorus } \\
\text { mineralization }\end{array}$ \\
\hline$\beta$-xylosidase $(B X)$ & 4-MUB $\beta$-D-xylopyranoside & $\begin{array}{l}\text { C Cycle: Degrades cellulose \& } \\
\text { hemicellulose }\end{array}$ \\
\hline $\begin{array}{l}\beta \text {-glucuronidase } \\
(B G L U)\end{array}$ & 4-MUB $\beta$-D-glucuronide & C Cycle: Degrades hemicellulose \\
\hline
\end{tabular}

416

417 
431 Supplemental Table 2 Pairwise comparisons of Bray-Curtis distance between all

432 treatments. *Denotes significance with FDR correction.

\begin{tabular}{|c|c|c|c|c|}
\hline Comparison & Sum of Squares & $\mathbf{F}$ & $\mathbf{r}^{2}$ & Adjusted p \\
\hline \multicolumn{5}{|c|}{ Solo vs Solo } \\
\hline Maple vs Birch & 0.675 & 4.585 & 0.247 & $0.001 *$ \\
\hline Maple vs Oak & 0.655 & 4.154 & 0.229 & $0.001 *$ \\
\hline Birch vs Oak & 1.080 & 6.550 & 0.319 & $0.003 *$ \\
\hline \multicolumn{5}{|c|}{ Solo vs Paired } \\
\hline Maple vs Birch \& Maple & 0.517 & 3.087 & 0.192 & 0.001* \\
\hline Maple vs Oak \& Maple & 0.864 & 4.975 & 0.277 & $0.001 *$ \\
\hline Maple vs Oak \& Birch & 0.820 & 4.308 & 0.264 & $0.001 *$ \\
\hline Birch vs Birch \& Maple & 0.691 & 3.943 & 0.233 & $0.003 *$ \\
\hline Birch vs Oak \& Maple & 0.928 & 5.106 & 0.282 & $0.001 *$ \\
\hline Birch vs Oak \& Birch & 0.880 & 4.423 & 0.269 & $0.004 *$ \\
\hline Oak vs Birch \& Maple & 0.468 & 2.511 & 0.162 & $0.001 *$ \\
\hline Oak vs Oak \& Maple & 0.402 & 2.086 & 0.138 & $0.002 *$ \\
\hline Oak vs Oak \& Birch & 0.438 & 2.072 & 0.147 & $0.007 *$ \\
\hline \multicolumn{5}{|c|}{ Solo vs All } \\
\hline Maple vs All Trees & 0.766 & 4.730 & 0.301 & $0.001 *$ \\
\hline Birch vs All Trees & 0.919 & 5.366 & 0.328 & $0.003 *$ \\
\hline Oak vs All Trees & 0.492 & 2.666 & 0.195 & $0.001 *$ \\
\hline \multicolumn{5}{|c|}{ Paired vs Paired } \\
\hline Birch \& Maple vs Oak \& Maple & 0.543 & 2.631 & 0.180 & 0.003* \\
\hline Birch \& Maple vs Oak \& Birch & 0.542 & 2.382 & 0.178 & $0.001 *$ \\
\hline Oak \& Maple vs Oak \& Birch & 0.265 & 1.126 & 0.093 & 0.239 \\
\hline \multicolumn{5}{|c|}{ Paired vs All } \\
\hline Oak \& Maple vs All Trees & 0.263 & 1.262 & 0.112 & 0.060 \\
\hline Oak \& Birch vs All Trees & 0.268 & 1.146 & 0.113 & 0.242 \\
\hline Birch \& Maple vs All Trees & 0.517 & 2.585 & 0.205 & $0.004 *$ \\
\hline
\end{tabular}




\section{DECLARATIONS}

440 Conflicts of Interest

441 The authors declare that the research was conducted in the absence of any commercial or financial

442 relationships that could be construed as a potential conflict of interest.

443

$444 \quad$ Funding

445 The research leading to these results was funded by the Fordham University Graduate Research fund and

446 the Louis Calder Center.

447

Acknowledgments

449 We thank the Louis Calder Center for use of their facilities including the Calder Forest and the

450 greenhouse. We also thank Drs. Steven Franks, John Wehr, and Patricio Meneses for their feedback on

451 earlier drafts of this manuscript. 


\section{REFERENCES}

Abarenkov, K., Henrik Nilsson, R., Larsson, K. H., Alexander, I. J., Eberhardt, U., Erland, S., ... \& Kõljalg, U. (2010). The UNITE database for molecular identification of fungi-recent updates and future perspectives. New Phytologist, 186(2), 281-285.

Aponte, C., García, L. V., Marañón, T., \& Gardes, M. (2010). Indirect host effect on ectomycorrhizal fungi: Leaf fall and litter quality explain changes in fungal communities on the roots of cooccurring Mediterranean oaks. Soil Biology and Biochemistry, 42(5), 788-796.

Baldrian, P. (2014). Distribution of extracellular enzymes in soils: spatial heterogeneity and determining factors at various scales. Soil Science Society of America Journal, 78(1), 11-18.

Baldrian, P. (2017). Forest microbiome: diversity, complexity and dynamics. FEMS Microbiology reviews, 41(2), 109-130.

Bardgett, R. D., \& Wardle, D. A. (2010). Aboveground-belowground linkages: biotic interactions, ecosystem processes, and global change. Oxford University Press.

Bardgett, R. D., \& Van Der Putten, W. H. (2014). Belowground biodiversity and ecosystem functioning. Nature, 515(7528), 505-511.

Barnes, E.M., Kutos, S., Naghshineh, N., Mesko, M., You, Q. and Lewis, J.D. (2021), Assembly of the amphibian microbiome is influenced by the effects of land-use change on environmental reservoirs. Environ Microbiol.

Bell, C. W., Fricks, B. E., Rocca, J. D., Steinweg, J. M., McMahon, S. K., \& Wallenstein, M. D. (2013). High throughput fluorometric measurement of potential soil extracellular enzyme activities. JoVE (Journal of Visualized Experiments), (81), e50961.

Boer, W. D., Folman, L. B., Summerbell, R. C., \& Boddy, L. (2005). Living in a fungal world: impact of fungi on soil bacterial niche development. FEMS Microbiology Reviews, 29(4), 795-811.

Bogar, L. M., \& Kennedy, P. G. (2013). New wrinkles in an old paradigm: neighborhood effects can modify the structure and specificity of Alnus-associated ectomycorrhizal fungal communities. FEMS Microbiology Ecology, 83(3), 767-777.

Bogar, L. M., Dickie, I. A., \& Kennedy, P. G. (2015). Testing the co-invasion hypothesis: ectomycorrhizal fungal communities on Alnus glutinosa and Salix fragilis in New Zealand. Diversity and Distributions, 21(3), 268-278.

Botnen, S., Vik, U., Carlsen, T., Eidesen, P. B., Davey, M. L., \& Kauserud, H. (2014). Low host specificity of root-associated fungi at an Arctic site. Molecular Ecology, 23(4), 975-985.

Boberg, J. B., Ihrmark, K., \& Lindahl, B. D. (2011). Decomposing capacity of fungi commonly detected in Pinus sylvestris needle litter. Fungal Ecology, 4(1), 110-114.

Brockett, B. F., Prescott, C. E., \& Grayston, S. J. (2012). Soil moisture is the major factor influencing microbial community structure and enzyme activities across seven biogeoclimatic zones in western Canada. Soil Biology and Biochemistry, 44(1), 9-20.

Buée, M., Reich, M., Murat, C., Morin, E., Nilsson, R. H., Uroz, S., \& Martin, F. (2009). 454 Pyrosequencing analyses of forest soils reveal an unexpectedly high fungal diversity. New Phytologist, 184(2), 449-456.

Burns, R. G. (1982). Enzyme activity in soil: location and a possible role in microbial ecology. Soil Biology and Biochemistry, 14(5), 423-427.

Burns, R. G., DeForest, J. L., Marxsen, J., Sinsabaugh, R. L., Stromberger, M. E., Wallenstein, M. D., ... \& Zoppini, A. (2013). Soil enzymes in a changing environment: current knowledge and future directions. Soil Biology and Biochemistry, 58, 216-234.

Butler-Leopold, P. R., Iverson, L. R., Thompson, F. R., Brandt, L. A., Handler, S. D., Janowiak, M. K., ... \& Clark, K. L. (2018). Mid-Atlantic forest ecosystem vulnerability assessment and synthesis: a report from the Mid-Atlantic Climate Change Response Framework project. Gen. Tech. Rep. NRS-181. Newtown Square, PA: US Department of Agriculture, Forest Service, Northern Research Station. 294 p., 181, 1-294. 
Cáceres, M. D., \& Legendre, P. (2009). Associations between species and groups of sites: indices and statistical inference. Ecology, 90(12), 3566-3574.

Callahan, B. J., McMurdie, P. J., Rosen, M. J., Han, A. W., Johnson, A. J. A., \& Holmes, S. P. (2016). DADA2: high-resolution sample inference from Illumina amplicon data. Nature Methods, 13(7), 581-583.

Caporaso, J. G., Kuczynski, J., Stombaugh, J., Bittinger, K., Bushman, F. D., Costello, E. K., ... \& Knight, R. (2010). QIIME allows analysis of high-throughput community sequencing data. Nature Methods, 7(5), 335-336.

Castledine, M., Sierocinski, P., Padfield, D., \& Buckling, A. (2020). Community coalescence: an ecoevolutionary perspective. Philosophical Transactions of the Royal Society B, 375(1798), 20190252.

Chalot, M., \& Brun, A. (1998). Physiology of organic nitrogen acquisition by ectomycorrhizal fungi and ectomycorrhizas. FEMS Microbiology Reviews, 22(1), 21-44.

Courty, P. E., Pritsch, K., Schloter, M., Hartmann, A., \& Garbaye, J. (2005). Activity profiling of ectomycorrhiza communities in two forest soils using multiple enzymatic tests. New Phytologist, 167(1), 309-319.

Dale, V. H., Joyce, L. A., McNulty, S., Neilson, R. P., Ayres, M. P., Flannigan, M. D., ... \& Wotton, B. M. (2001). Climate change and forest disturbances: climate change can affect forests by altering the frequency, intensity, duration, and timing of fire, drought, introduced species, insect and pathogen outbreaks, hurricanes, windstorms, ice storms, or landslides. BioScience, 51(9), 723 734.

Damm, U., Fourie, P. H., \& Crous, P. W. (2010). Coniochaeta (Lecythophora), Collophora gen. nov. and Phaeomoniella species associated with wood necroses of Prunus trees. Persoonia: Molecular Phylogeny and Evolution of Fungi, 24, 60.

De Deyn, G. B., \& Van der Putten, W. H. (2005). Linking aboveground and belowground diversity. Trends in Ecology \& Evolution, 20(11), 625-633.

DeForest, J. L. (2009). The influence of time, storage temperature, and substrate age on potential soil enzyme activity in acidic forest soils using MUB-linked substrates and L-DOPA. Soil Biology and Biochemistry, 41(6), 1180-1186.

Dickie, I. A. N., \& Reich, P. B. (2005). Ectomycorrhizal fungal communities at forest edges. Journal of Ecology, 93(2), 244-255.

Dickie, I. A. (2007). Host preference, niches and fungal diversity. The New Phytologist, 174(2), 230-233.

Edwards, I. P., \& Zak, D. R. (2010). Phylogenetic similarity and structure of Agaricomycotina communities across a forested landscape. Molecular Ecology, 19(7), 1469-1482.

Ekanayaka, A. H., Hyde, K. D., Gentekaki, E., McKenzie, E. H. C., Zhao, Q., Bulgakov, T. S., \& Camporesi, E. (2019). Preliminary classification of Leotiomycetes. Mycosphere, 10(1), 310-489.

Ellegaard-Jensen, L., Aamand, J., Kragelund, B. B., Johnsen, A. H., \& Rosendahl, S. (2013). Strains of the soil fungus Mortierella show different degradation potentials for the phenylurea herbicide diuron. Biodegradation, 24(6), 765-774.

Egidi, E., Delgado-Baquerizo, M., Plett, J. M., Wang, J., Eldridge, D. J., Bardgett, R. D., ... \& Singh, B. K. (2019). A few Ascomycota taxa dominate soil fungal communities worldwide. Nature Communications, 10(1), 1-9.

Essene, A. L., Shek, K. L., Lewis, J. D., Peay, K. G., \& McGuire, K. L. (2017). Soil type has a stronger role than Dipterocarp host species in shaping the ectomycorrhizal fungal community in a Bornean lowland tropical rain forest. Frontiers in Plant Science, 8, 1828.

Fontaine, S., Hénault, C., Aamor, A., Bdioui, N., Bloor, J. M. G., Maire, V., ... \& Maron, P. A. (2011). Fungi mediate long term sequestration of carbon and nitrogen in soil through their priming effect. Soil Biology and Biochemistry, 43(1), 86-96.

Gao, C., Montoya, L., Xu, L., Madera, M., Hollingsworth, J., Purdom, E., ... \& Taylor, J. W. (2020). Fungal community assembly in drought-stressed sorghum shows stochasticity, selection, and universal ecological dynamics. Nature Communications, 11(1), 1-14. 
Gardes, M., \& Bruns, T. D. (1993). ITS primers with enhanced specificity for basidiomycetes-application to the identification of mycorrhizae and rusts. Molecular Ecology, 2(2), 113-118.

Glassman, S. I., Weihe, C., Li, J., Albright, M. B., Looby, C. I., Martiny, A. C., ... \& Martiny, J. B. (2018). Decomposition responses to climate depend on microbial community composition. Proceedings of the National Academy of Sciences, 115(47), 11994-11999.

Guerra, C. A., Heintz-Buschart, A., Sikorski, J., Chatzinotas, A., Guerrero-Ramírez, N., Cesarz, S., ... \& Buscot, F. (2020). Blind spots in global soil biodiversity and ecosystem function research. Nature Communications, 11(1), 1-13.

Hart, M. M., Reader, R. J., \& Klironomos, J. N. (2003). Plant coexistence mediated by arbuscular mycorrhizal fungi. Trends in Ecology \& Evolution, 18(8), 418-423.

Hausmann, N. T., \& Hawkes, C. V. (2009). Plant neighborhood control of arbuscular mycorrhizal community composition. New Phytologist, 183(4), 1188-1200.

Hennebert, G. L., \& Korf, R. P. (1975). The peat mould, Chromelosporium ollare, conidial state of Peziza ostracoderma, and its misapplied names, Botrytis crystallina, Botrytis spectabilis, Ostracoderma epigaeum and Peziza atrovinosa. Mycologia, 67(2), 214-240.

Horton, T. R., \& Bruns, T. D. (1998). Multiple-host fungi are the most frequent and abundant ectomycorrhizal types in a mixed stand of Douglas fir (Pseudotsuga menziesii) and bishop pine (Pinus muricata). New Phytologist, 139(2), 331-339.

Hrynkiewicz, K., Szymańska, S., Piernik, A., \& Thiem, D. (2015). Ectomycorrhizal community structure of Salix and Betula spp. at a saline site in central Poland in relation to the seasons and soil parameters. Water, Air, \& Soil Pollution, 226(4), 1-15.

Hubert, N. A., \& Gehring, C. A. (2008). Neighboring trees affect ectomycorrhizal fungal community composition in a woodland-forest ecotone. Mycorrhiza, 18(6-7), 363-374.

Ishida, T. A., Nara, K., \& Hogetsu, T. (2007). Host effects on ectomycorrhizal fungal communities: insight from eight host species in mixed conifer-broadleaf forests. New Phytologist, 174(2), 430440.

Jacks, T. J., \& Kircher, H. W. (1967). Fluorometric assay for the hydrolytic activity of lipase using fatty acyl esters of 4-methylumbelliferone. Analytical Biochemistry, 21(2), 279-285.

Jo, I., Fei, S., Oswalt, C. M., Domke, G. M., \& Phillips, R. P. (2019). Shifts in dominant tree mycorrhizal associations in response to anthropogenic impacts. Science Advances, 5(4), eaav6358.

Johnson, J. M., Ludwig, A., Furch, A. C., Mithöfer, A., Scholz, S., Reichelt, M., \& Oelmüller, R. (2019). The beneficial root-colonizing fungus Mortierella hyalina promotes the aerial growth of Arabidopsis and activates calcium-dependent responses that restrict Alternaria brassicae-Induced disease development in roots. Molecular Plant-Microbe Interactions, 32(3), 351-363.

Karst, J., Erbilgin, N., Pec, G. J., Cigan, P. W., Najar, A., Simard, S. W., \& Cahill Jr, J. F. (2015). Ectomycorrhizal fungi mediate indirect effects of a bark beetle outbreak on secondary chemistry and establishment of pine seedlings. New Phytologist, 208(3), 904-914.

Kennedy, P. G., Smith, D. P., Horton, T. R., \& Molina, R. J. (2012). Arbutus menziesii (Ericaceae) facilitates regeneration dynamics in mixed evergreen forests by promoting mycorrhizal fungal diversity and host connectivity. American Journal of Botany, 99(10), 1691-1701.

Klironomos, J. N. (2000). Host-specificity and functional diversity among arbuscular mycorrhizal fungi. Microbial Biosystems: New Frontiers, 1, 845-851.

Kiers, E. T., Duhamel, M., Beesetty, Y., Mensah, J. A., Franken, O., Verbruggen, E., ... \& Bücking, H. (2011). Reciprocal rewards stabilize cooperation in the mycorrhizal symbiosis. Science, 333(6044), 880-882.

Kivlin, S. N., \& Treseder, K. K. (2014). Soil extracellular enzyme activities correspond with abiotic factors more than fungal community composition. Biogeochemistry, 117(1), 23-37.

Koechli, C., Campbell, A. N., Pepe-Ranney, C., \& Buckley, D. H. (2019). Assessing fungal contributions to cellulose degradation in soil by using high-throughput stable isotope probing. Soil Biology and Biochemistry, 130, 150-158. 
Kurtzman, C. P., \& Robnett, C. J. (2007). Multigene phylogenetic analysis of the Trichomonascus, Wickerhamiella and Zygoascus yeast clades, and the proposal of Sugiyamaella gen. nov. and 14 new species combinations. FEMS Yeast Research, 7(1), 141-151.

Kyaschenko, J., Clemmensen, K. E., Hagenbo, A., Karltun, E., \& Lindahl, B. D. (2017). Shift in fungal communities and associated enzyme activities along an age gradient of managed Pinus sylvestris stands. The ISME Journal, 11(4), 863-874.

Lang, C., Seven, J., \& Polle, A. (2011). Host preferences and differential contributions of deciduous tree species shape mycorrhizal species richness in a mixed Central European forest. Mycorrhiza, 21(4), 297-308.

Lahti, L., Shetty, S., Blake, T., \& Salojarvi, J. (2017). Tools for microbiome analysis in R. Version, 1(10013), 504.

Leff, J. W., Bardgett, R. D., Wilkinson, A., Jackson, B. G., Pritchard, W. J., Jonathan, R., ... \& Fierer, N. (2018). Predicting the structure of soil communities from plant community taxonomy, phylogeny, and traits. The ISME Journal, 12(7), 1794-1805.

Li, J. H., Cheng, B. H., Zhang, R., Li, W. J., Shi, X. M., Han, Y. W., ... \& Bardgett, R. D. (2021). Nitrogen and phosphorus additions accelerate decomposition of slow carbon pool and lower total soil organic carbon pool in alpine meadows. Land Degradation \& Development, 32(4), 17611772.

Liu, X. Z., Wang, Q. M., Theelen, B., Groenewald, M., Bai, F. Y., \& Boekhout, T. (2015). Phylogeny of tremellomycetous yeasts and related dimorphic and filamentous basidiomycetes reconstructed from multiple gene sequence analyses. Studies in Mycology, 81, 1-26.

Lladó, S., López-Mondéjar, R., \& Baldrian, P. (2018). Drivers of microbial community structure in forest soils. Applied Microbiology and Biotechnology, 102(10), 4331-4338.

Looby, C. I., \& Treseder, K. K. (2018). Shifts in soil fungi and extracellular enzyme activity with simulated climate change in a tropical montane cloud forest. Soil Biology and Biochemistry, 117, 87-96.

Looney, B. P., Meidl, P., Piatek, M. J., Miettinen, O., Martin, F. M., Matheny, P. B., \& Labbé, J. L. (2018). Russulaceae: a new genomic dataset to study ecosystem function and evolutionary diversification of ectomycorrhizal fungi with their tree associates. New Phytologist, 218(1), 5465.

López, M. J., Nichols, N. N., Dien, B. S., Moreno, J., \& Bothast, R. J. (2004). Isolation of microorganisms for biological detoxification of lignocellulosic hydrolysates. Applied Microbiology and Biotechnology, 64(1), 125-131.

Lynd, L. R., Weimer, P. J., Van Zyl, W. H., \& Pretorius, I. S. (2002). Microbial cellulose utilization: fundamentals and biotechnology. Microbiology and Molecular Biology reviews, 66(3), 506-577.

Mangan, S. A., Schnitzer, S. A., Herre, E. A., Mack, K. M., Valencia, M. C., Sanchez, E. I., \& Bever, J. D. (2010). Negative plant-soil feedback predicts tree-species relative abundance in a tropical forest. Nature, 466(7307), 752-755.

Martin, M. (2011). Cutadapt removes adapter sequences from high-throughput sequencing reads. EMBnet. Journal, 17(1), 10-12.

Martinez Arbizu, P. (2017). pairwiseAdonis: Pairwise multilevel comparison using adonis. $R$ package version $0.0,1$.

Martiny, J. B. H., Bohannan, B. J., Brown, J. H., Colwell, R. K., Fuhrman, J. A., Green, J. L., ... \& Staley, J. T. (2006). Microbial biogeography: putting microorganisms on the map. Nature Reviews Microbiology, 4(2), 102-112.

Marx, M. C., Wood, M., \& Jarvis, S. C. (2001). A microplate fluorimetric assay for the study of enzyme diversity in soils. Soil Biology and Biochemistry, 33(12-13), 1633-1640.

Mašínová, T., Bahnmann, B. D., Větrovský, T., Tomšovský, M., Merunková, K., \& Baldrian, P. (2017). Drivers of yeast community composition in the litter and soil of a temperate forest. FEMS Microbiology Ecology, 93(2). 
701

702

703

704

705

706

707

708

709

710

711

712

Massicotte, H. B., Molina, R., Tackaberry, L. E., Smith, J. E., \& Amaranthus, M. P. (1999). Diversity and host specificity of ectomycorrhizal fungi retrieved from three adjacent forest sites by five host species. Canadian Journal of Botany, 77(8), 1053-1076

McMurdie, P. J., \& Holmes, S. (2013). phyloseq: An R package for reproducible interactive analysis and graphics of microbiome census data. PloS one, 8(4), e61217.

Miettinen, O., Spirin, V., Vlasák, J., Rivoire, B., Stenroos, S., \& Hibbett, D. (2016). Polypores and genus concepts in Phanerochaetaceae (Polyporales, Basidiomycota). MycoKeys, 17, 1.

Millanes, A. M., Diederich, P., Ekman, S., \& Wedin, M. (2011). Phylogeny and character evolution in the jelly fungi (Tremellomycetes, Basidiomycota, Fungi). Molecular Phylogenetics and Evolution, 61(1), 12-28.

Moeller, H. V., Dickie, I. A., Peltzer, D. A., \& Fukami, T. (2015). Mycorrhizal co-invasion and novel interactions depend on neighborhood context. Ecology, 96(9), 2336-2347.

Molina, R., \& Trappe, J. M. (1982). Patterns of ectomycorrhizal host specificity and potential among Pacific Northwest conifers and fungi. Forest Science, 28(3), 423-458.

Molina, R., \& Horton, T. R. (2015). Mycorrhiza specificity: its role in the development and function of common mycelial networks. In Mycorrhizal Networks (pp. 1-39). Springer, Dordrecht.

Morris, M. H., Perez-Perez, M. A., Smith, M. E., \& Bledsoe, C. S. (2009). Influence of host species on ectomycorrhizal communities associated with two co-occurring oaks (Quercus spp.) in a tropical cloud forest. FEMS Microbiology Ecology, 69(2), 274-287.

Moser, W. K., Butler-Leopold, P., Hausman, C., Iverson, L., Ontl, T., Brand, L., ... \& Prasad, A. (2020). The impact of climate change on forest systems in the northern United States: Projections and implications for forest management [Chapter 8]. In: Achieving sustainable management of boreal and temperate forests. Cambridge, UK: Burleigh and Dodds Science Publishing. p 239-290., 239-290.

Mummey, D. L., Rillig, M. C., \& Holben, W. E. (2005). Neighboring plant influences on arbuscular mycorrhizal fungal community composition as assessed by T-RFLP analysis. Plant and Soil, 271(1), 83-90.

Nannipieri, P., Giagnoni, L., Renella, G., Puglisi, E., Ceccanti, B., Masciandaro, G., ... \& Marinari, S. A. R. A. (2012). Soil enzymology: classical and molecular approaches. Biology and Fertility of Soils, 48(7), 743-762.

Nannipieri, P., Trasar-Cepeda, C., \& Dick, R. P. (2018). Soil enzyme activity: a brief history and biochemistry as a basis for appropriate interpretations and meta-analysis. Biology and Fertility of Soils, 54(1), 11-19.

Nara, K. (2006). Ectomycorrhizal networks and seedling establishment during early primary succession. New Phytologist, 169(1), 169-178.

Nguyen, N. H., Song, Z., Bates, S. T., Branco, S., Tedersoo, L., Menke, J., ... \& Kennedy, P. G. (2016). FUNGuild: an open annotation tool for parsing fungal community datasets by ecological guild. Fungal Ecology, 20, 241-248.

Oksanen, J., Kindt, R., Legendre, P., O’Hara, B., Stevens, M. H. H., Oksanen, M. J., \& Suggests, M. A. S. S. (2007). The vegan package. Community ecology package, 10(631-637), 719.

Pearce, D. W. (2001). The economic value of forest ecosystems. Ecosystem Health, 7(4), 284-296.

Peay, K. G., \& Bruns, T. D. (2014). Spore dispersal of basidiomycete fungi at the landscape scale is driven by stochastic and deterministic processes and generates variability in plant-fungal interactions. New Phytologist, 204(1), 180-191.

Péter, G., Dlauchy, D., Price, N. P., \& Kurtzman, C. P. (2012). Diddensiella caesifluorescens gen. nov., $s p$. nov., a riboflavin-producing yeast species of the family Trichomonascaceae. International journal of systematic and evolutionary microbiology, 62(12), 3081-3087.

Poll, C., Brune, T., Begerow, D., \& Kandeler, E. (2010). Small-scale diversity and succession of fungi in the detritusphere of rye residues. Microbial Ecology, 59(1), 130-140. 
Prober, S. M., Leff, J. W., Bates, S. T., Borer, E. T., Firn, J., Harpole, W. S., ... \& Fierer, N. (2015). Plant diversity predicts beta but not alpha diversity of soil microbes across grasslands worldwide. Ecology Letters, 18(1), 85-95.

Ramirez, K. S., Leff, J. W., Barberán, A., Bates, S. T., Betley, J., Crowther, T. W., ... \& Fierer, N. (2014). Biogeographic patterns in below-ground diversity in New York City's Central Park are similar to those observed globally. Proceedings of the royal society B: biological sciences, 281(1795), 20141988.

Reese, A. T., Savage, A., Youngsteadt, E., McGuire, K. L., Koling, A., Watkins, O., ... \& Dunn, R. R. (2016). Urban stress is associated with variation in microbial species composition-but not richness - in Manhattan. The ISME journal, 10(3), 751-760.

Rillig, M. C., Lehmann, A., Aguilar-Trigueros, C. A., Antonovics, J., Caruso, T., Hempel, S., ... \& Powell, J. R. (2016). Soil microbes and community coalescence. Pedobiologia, 59(1-2), 37-40.

Rivers, A. R., Weber, K. C., Gardner, T. G., Liu, S., \& Armstrong, S. D. (2018). ITSxpress: software to rapidly trim internally transcribed spacer sequences with quality scores for marker gene analysis. F1000Research, 7.

Rohland, N., \& Reich, D. (2012). Cost-effective, high-throughput DNA sequencing libraries for multiplexed target capture. Genome Research, 22(5), 939-946.

Romaní, A. M., Fischer, H., Mille-Lindblom, C., \& Tranvik, L. J. (2006). Interactions of bacteria and fungi on decomposing litter: differential extracellular enzyme activities. Ecology, 87(10), 25592569.

Rousk, J., Bååth, E., Brookes, P. C., Lauber, C. L., Lozupone, C., Caporaso, J. G., ... \& Fierer, N. (2010). Soil bacterial and fungal communities across a $\mathrm{pH}$ gradient in an arable soil. The ISME Journal, 4(10), 1340-1351.

Ryberg, M., Larsson, E., \& Molau, U. (2009). Ectomycorrhizal diversity on Dryas octopetala and Salix reticulata in an alpine cliff ecosystem. Arctic, Antarctic, and Alpine Research, 41(4), 506-514.

Sánchez, S., Gómez, E., Martín, M., De Miguel, A. M., Urban, A., \& Barriuso, J. (2014). Experiments on the life cycle and factors affecting reproduction of Sphaerosporella brunnea provide evidence for rapid asexual propagation by conidiospores and for homothallism in an ectomycorrhizal competitor of cultivated truffle species. Fungal Ecology, 8, 59-65.

Saunders, M., \& Kohn, L. M. (2009). Evidence for alteration of fungal endophyte community assembly by host defense compounds. New Phytologist, 182(1), 229-238.

Sinsabaugh, R. L., \& Moorhead, D. L. (1994). Resource allocation to extracellular enzyme production: a model for nitrogen and phosphorus control of litter decomposition. Soil Biology and Biochemistry, 26(10), 1305-1311.

Smith, D. P., \& Peay, K. G. (2014). Sequence depth, not PCR replication, improves ecological inference from next generation DNA sequencing. PloS one, 9(2), e90234.

Smith, M. E., Henkel, T. W., Catherine Aime, M., Fremier, A. K., \& Vilgalys, R. (2011). Ectomycorrhizal fungal diversity and community structure on three co-occurring leguminous canopy tree species in a Neotropical rainforest. New Phytologist, 192(3), 699-712.

Smith, S. E., \& Read, D. J. (2010). Mycorrhizal symbiosis. Academic press.

Strickland, M. S., Lauber, C., Fierer, N., \& Bradford, M. A. (2009). Testing the functional significance of microbial community composition. Ecology, 90(2), 441-451.

Talbot, J. M., Bruns, T. D., Taylor, J. W., Smith, D. P., Branco, S., Glassman, S. I., ... \& Peay, K. G. (2014). Endemism and functional convergence across the North American soil mycobiome. Proceedings of the National Academy of Sciences, 111(17), 6341-6346.

Tedersoo, L., Suvi, T., Jairus, T., \& Kõljalg, U. (2008). Forest microsite effects on community composition of ectomycorrhizal fungi on seedlings of Picea abies and Betula pendula. Environmental microbiology, 10(5), 1189-1201.

Tedersoo, L., Sadam, A., Zambrano, M., Valencia, R., \& Bahram, M. (2010). Low diversity and high host preference of ectomycorrhizal fungi in Western Amazonia, a neotropical biodiversity hotspot. The ISME Journal, 4(4), 465-471. 
Tedersoo, L., Bahram, M., Toots, M., Diedhiou, A. G., Henkel, T. W., Kjøller, R., ... \& Koljalg, U. (2012). Towards global patterns in the diversity and community structure of ectomycorrhizal fungi. Molecular Ecology, 21(17), 4160-4170.

Tedersoo, L., \& Smith, M. E. (2013). Lineages of ectomycorrhizal fungi revisited: foraging strategies and novel lineages revealed by sequences from belowground. Fungal Biology Reviews, 27(3-4), 8399.

Tedersoo, L., Bahram, M., Põlme, S., Kõljalg, U., Yorou, N. S., Wijesundera, R., ... \& Abarenkov, K. (2014). Global diversity and geography of soil fungi. Science, 346(6213).

Tedersoo, L., Anslan, S., Bahram, M., Drenkhan, R., Pritsch, K., Buegger, F., ... \& Abarenkov, K. (2020). Regional-scale in-depth analysis of soil fungal diversity reveals strong $\mathrm{pH}$ and plant species effects in Northern Europe. Frontiers in Microbiology, 11, 1953.

Turner, G. D., Lewis, J. D., Mates-Muchin, J. T., Schuster, W. F., \& Watt, L. (2009). Light availability and soil source influence ectomycorrhizal fungal communities on oak seedlings grown in oak-and hemlock-associated soils. Canadian Journal of Forest Research, 39(7), 1247-1258.

Uehling, J., Gryganskyi, A., Hameed, K., Tschaplinski, T., Misztal, P. K., Wu, S., ... \& Bonito, G. (2017). Comparative genomics of Mortierella elongata and its bacterial endosymbiont Mycoavidus cysteinexigens. Environmental Microbiology, 19(8), 2964-2983.

Urbanová, M., Šnajdr, J., \& Baldrian, P. (2015). Composition of fungal and bacterial communities in forest litter and soil is largely determined by dominant trees. Soil Biology and Biochemistry, 84, 53-64.

van der Heijden, M. G., Klironomos, J. N., Ursic, M., Moutoglis, P., Streitwolf-Engel, R., Boller, T., ... \& Sanders, I. R. (1998). Mycorrhizal fungal diversity determines plant biodiversity, ecosystem variability and productivity. Nature, 396(6706), 69-72.

van der Heijden, M. G., Bardgett, R. D., \& Van Straalen, N. M. (2008). The unseen majority: soil microbes as drivers of plant diversity and productivity in terrestrial ecosystems. Ecology Letters, 11(3), 296-310.

van der Linde, S., Suz, L. M., Orme, C. D. L., Cox, F., Andreae, H., Asi, E., ... \& Bidartondo, M. I. (2018). Environment and host as large-scale controls of ectomycorrhizal fungi. Nature, 558(7709), 243-248.

Wagg, C., Jansa, J., Stadler, M., Schmid, B., \& Van Der Heijden, M. G. (2011). Mycorrhizal fungal identity and diversity relaxes plant-plant competition. Ecology, 92(6), 1303-1313.

White, T. J., Bruns, T., Lee, S. J. W. T., \& Taylor, J. (1990). Amplification and direct sequencing of fungal ribosomal RNA genes for phylogenetics. PCR protocols: a guide to methods and applications, 18(1), 315-322.

Wickham, H. (2009). ggplot2: elegant graphics for data analysis (use R!). Springer, New York, 10, 978-0.

Wilson, A. W., Hosaka, K., \& Mueller, G. M. (2017). Evolution of ectomycorrhizas as a driver of diversification and biogeographic patterns in the model mycorrhizal mushroom genus Laccaria. New Phytologist, 213(4), 1862-1873

Wolfe, B. E., \& Pringle, A. (2012). Geographically structured host specificity is caused by the range expansions and host shifts of a symbiotic fungus. The ISME Journal, 6(4), 745-755.

Yamamoto, N., Bibby, K., Qian, J., Hospodsky, D., Rismani-Yazdi, H., Nazaroff, W. W., \& Peccia, J. (2012). Particle-size distributions and seasonal diversity of allergenic and pathogenic fungi in outdoor air. The ISME Journal, 6(10), 1801-1811.

Zhou, J., Deng, Y., Shen, L., Wen, C., Yan, Q., Ning, D., ... \& Brown, J. H. (2016). Temperature mediates continental-scale diversity of microbes in forest soils. Nature Communications, 7(1), 110.

Zobel, M., \& Öpik, M. (2014). Plant and arbuscular mycorrhizal fungal (AMF) communities-which drives which? Journal of Vegetation Science, 25(5), 1133-1140. 